\title{
Reproductive Decision-Making and Periconception Practices Among HIV-Positive Men and Women Attending HIV Services in Durban, South Africa
}

\author{
Lynn T. Matthews • Tamaryn Crankshaw • \\ Janet Giddy $\cdot$ Angela Kaida $\cdot$ Jennifer A. Smit • \\ Norma C. Ware · David R. Bangsberg
}

Published online: 29 October 2011

(c) The Author(s) 2011. This article is published with open access at Springerlink.com

\begin{abstract}
Understanding reproductive decisions and periconception behavior among HIV-discordant couples is important for designing risk reduction interventions for couples who choose to conceive. In-depth interviews were conducted to explore reproductive decision-making and periconception practices among HIV-positive women with recent pregnancy $(n=30)$, and HIV-positive men $(n=20)$, all reporting partners of negative or unknown HIV-status, and attending HIV services in Durban, South Africa. Transcripts were coded for categories and emergent themes.
\end{abstract}

L. T. Matthews $(\bowtie) \cdot$ D. R. Bangsberg

Division of Infectious Diseases and Center for Global Health,

Massachusetts General Hospital, 100 Cambridge Street, 15th

Floor, Boston, MA 02114, USA

e-mail: 1tmatthews@partners.org

L. T. Matthews

Division of Infectious Diseases, Beth Israel Deaconess Medical

Center, Boston, MA, USA

T. Crankshaw $\cdot$ J. Giddy

McCord Hospital, PMTCT, Durban, South Africa

A. Kaida

Faculty of Health Sciences, Simon Fraser University,

Vancouver, BC, Canada

\section{J. A. Smit}

Maternal, Adolescent and Child Health Division (MatCH), Department of Obstetrics and Gynaecology, University of the Witwatersrand, Durban, South Africa

\section{N. C. Ware}

Department of Global Health and Social Medicine, Harvard Medical School, Boston, MA, USA

D. R. Bangsberg

Mbarara University of Science and Technology, Mbarara, Uganda
Participants expressed strong reasons for having children, but rarely knew how to reduce periconception HIV transmission. Pregnancy planning occurred on a spectrum ranging from explicitly intended to explicitly unintended, with many falling in between the two extremes. Male fertility desire and misunderstanding serodiscordance contributed to HIV risk behavior. Participants expressed openness to healthcare worker advice for safer conception and modified risk behavior post-conception, suggesting the feasibility of safer conception interventions which may target both men and women and include serodiscordance counseling and promotion of contraception.

Keywords HIV-serodiscordant couples - HIV prevention Safer conception $\cdot$ Family planning $\cdot$ South Africa

\section{Introduction}

In sub-Saharan Africa, the majority of new HIV infections occur in women of reproductive age [1]. HIV transmission in stable serodiscordant sexual partnerships exceeds $10 \%$ per year and may account for greater than $60 \%$ of new HIV infections in Africa [2,3]. The contribution of intended conception to incident HIV infection has not been measured; however, studies in the United States [4], Europe [5-7], and sub-Saharan Africa [8-17] report that 20-50\% of HIVpositive individuals desire children. Individuals who engage in unprotected sex to conceive with a positive partner face a high risk of infection. If pregnancy does occur, ongoing unprotected sex during pregnancy is associated with increased risk of HIV transmission, with HIV incidence as high as 10\% [18-20]. Nonetheless, fertility intentions and outcomes among serodiscordant couples remain high: among HIV-discordant couples in Uganda, 59\% expressed a 
desire to have children [12], while in Nairobi annual pregnancy incidence among discordant couples was $9.7 \%$, mostly occurring among women reporting fertility desire [21]. HIV-discordant couples are often advised not to have children, but complex cultural, economic, and social factors motivate many couples to reproduce [22-33]. Reproductive intentions may increase with improvement in access to antiretroviral therapy (ART) and the health and survival of people living with HIV [11, 34, 35].

HIV-discordant couples who desire children require strategies to protect HIV-negative partners and future children from HIV infection. Reproductive technologies including sperm washing are not widely accessible [36, 37], whereas behavioral strategies (e.g., home manual insemination and unprotected sex limited to peak fertility) and medical strategies (e.g., male circumcision and treatment for sexually transmitted infections) are potential elements of periconception HIV risk reduction for serodiscordant couples in resource-limited settings [38-45]. Suppressive ART for the positive partner or topical or systemic pre-exposure prophylaxis (PrEP) for the negative partner may provide additional prevention options [46-50]. Prior to developing pharmaco-behavioral interventions, it is important to understand how serodiscordant couples approach reproductive decisions and consider periconception transmission risk.

Our objectives were to explore reproductive decisionmaking, understanding of horizontal transmission risk, and knowledge or deployment of periconception risk-modification practices among HIV-positive men and women with serodiscordant sexual partners in a high HIV-prevalence setting.

\section{Methods}

Study Setting, Patient Selection, Inclusion, and Exclusion Criteria

McCord Hospital is a state-aided (public/private partnership) general hospital serving a predominantly-urban population from the greater Durban area where provincial antenatal clinic HIV-prevalence is estimated at 39.5\% [51]. The McCord HIV Clinic has provided care and treatment to approximately 7,000 patients on ART. Sixty percent of these patients are women; the majority $(>90 \%)$ are Zulu. Patients pay approximately $\sim 25$ USD per month for HIV services. Preventing Mother to Child Transmission (PMTCT) clinic services are free to those who access antenatal services $(\sim 35$ USD per visit); in 2010, 200 pregnant women enrolled.

Male participants were recruited from the general HIV clinic and female participants were recruited from the HIV and PMTCT clinics. Inclusion criteria were (1) age 18-45 years; (2) HIV-positive; (3) pregnancy in the prior
12 months (for women); (4) partner of unknown or seronegative HIV-status (prior to referent pregnancy) by participant report; (5) fluent in English or isiZulu; and (6) able to give informed consent.

\section{Procedures}

The research focus was to explore periconception risk understanding and practices. We aimed to describe as many new and different understandings and practices as possible. This requires an open-ended methodology based on an inductive approach to data collection and analysis [52]. We therefore conducted qualitative research with in-depth interviews to explore reproductive decision-making, horizontal transmission risk understanding and practices, and periconception risk understanding and practices. Participants were recruited through purposive sampling from patients awaiting clinical consultation. After obtaining informed consent, a gender-concordant research assistant interviewed participants in a private setting in isiZulu or English. Interviews were recorded, translated, and transcribed.

Transcripts were independently reviewed and coded, and resultant conceptual categories and emergent themes were discussed by the research team [52, 53]. The authors reviewed coding categories and emergent themes with the research assistants in order to explore additional themes and confirm accuracy of interpretation.

Ethics approvals were obtained from the McCord Hospital Research Ethics Committee (Durban, South Africa) and from the Partners Healthcare Institutional Review Board (Boston, USA).

\section{Results}

Demographics

Baseline demographic data, HIV history, reported partner HIV-status, and reproductive history for 30 female and 20 male participants are shown in Table 1 . Women and men averaged 30 (SD 4) and 34 (SD 6) years of age, respectively, and had been diagnosed with HIV for a mean of 3 years (SD 2 women, SD 5 men). Seventy-three percent of women and $60 \%$ of men had completed secondary school while $63 \%$ of women and $75 \%$ of men reported current employment. All women had a pregnancy in the past year and $73 \%$ were diagnosed with HIV prior to the referent pregnancy. Women had an average of 2.1 (SD 1.1) pregnancies (including current), 1.1 (SD 0.7) prior live births, 0.9 (SD 0.6) living children, and 18 (60\%) were pregnant. Men had an average of 0.9 (SD 1.0) living children; three $(16 \%)$ reported partner pregnancy in the past year. 
Table 1 Study population characteristics

\begin{tabular}{|c|c|c|}
\hline Characteristics & $\begin{array}{l}\text { Women } \\
(n=30)\end{array}$ & $\begin{array}{l}\text { Men } \\
(n=20)\end{array}$ \\
\hline Mean age \pm SD (years) & $30 \pm 4$ & $34 \pm 6$ \\
\hline Completed matric or above $^{\dagger}$ & $22(73 \%)$ & $12(60 \%)$ \\
\hline Employed & $19(63 \%)$ & $15(75 \%)$ \\
\hline Mean years since HIV diagnosis \pm SD & $3 \pm 2$ & $3 \pm 5$ \\
\hline Currently on ART/ARVs & $21(70 \%)$ & $17(85 \%)$ \\
\hline $\begin{array}{l}\text { HIV-negative (versus unknown status) } \\
\text { partner }\end{array}$ & $14(46 \%)$ & $13(65 \%)$ \\
\hline Disclosed HIV-status to partner* & $23(79 \%)$ & $15(78 \%)$ \\
\hline $\begin{array}{l}\text { Pregnancy or partner pregnancy in the } \\
\text { past year }\end{array}$ & $30(100 \%)$ & $3(16 \%)$ \\
\hline $\begin{array}{l}\text { Pregnancy or partner pregnancy since } \\
\text { HIV diagnosis }\end{array}$ & $22(73 \%)$ & $2(11 \%)$ \\
\hline $\begin{array}{l}\text { On ART prior to pregnancy or partner } \\
\text { pregnancy }\end{array}$ & $9 / 22(40 \%)$ & $\begin{array}{l}2 / 2 \\
(100 \%)\end{array}$ \\
\hline $\begin{array}{l}\text { Pregnancies, including current } \\
\quad(\text { mean } \pm \text { SD) }\end{array}$ & $2.1 \pm 1.1$ & - \\
\hline Live births (mean $\pm \mathrm{SD}$ ) & $1.1 \pm 0.7$ & - \\
\hline Currently living children (mean $\pm \mathrm{SD}$ ) & $0.9 \pm 0.6$ & $0.9 \pm 1.0$ \\
\hline Desire for child in future & $8(27 \%)$ & $14(70 \%)$ \\
\hline
\end{tabular}

\section{Overview}

The data are presented as periconception attitudes and practices of serodiscordant couples with the goal of informing interventions to reduce periconception HIV transmission. We first describe (1) reproductive decisionmaking. A priori, or pre-defined, categories included reasons for and deterrents to having children. Emergent themes included the role of men in pregnancy decisions and the spectrum of pregnancy planning. We then describe (2) horizontal transmission risk understanding and practices, and (3) periconception risk understanding and practices. A priori categories included knowledge and practice of safer sex strategies to prevent horizontal transmission in general and in the context of conception. An emergent theme was post-conception HIV risk reduction to protect the unborn child.

\section{Reproductive Decision-Making}

\section{A. Reasons for Having Children}

Most male participants in this sample expressed a desire for children in the future; those who did not desire children in the future reported at least one living child. They described a variety of motivations for having children including personal preference, family pressure, to continue the family name, to express manhood, to express commitment to a partner, or to increase social capital. Women described the importance of having children in order to meet marital or other responsibilities to a partner or his family, to avoid abandonment by a spouse, to fulfill responsibilities to her own family, for emotional gratification, and as an important manifestation of womanhood. For some, HIV infection and perceived imminent mortality conferred increased urgency on reproductive goals.

I think [it is important for a man to have children] because children are a gift from God. They leave a legacy of the family and they extend and expand your surname so that it won't die when you die, your legacy won't perish. [Man \#13, 28 years old, partner HIV-negative]

It is important [to have children] nowadays because if you are an only child to your parents and their hope is in you, if you get sick-because most of the time we young people die - then my child will grow up and help my mother when she is sick. So I see it as important. When you do not have children and you are married you find that your husband says that you must give him children because he paid a lot of money so you need to also produce in order to pay. If you tell him that you do not want any children he will go look for someone else who will have kids for him. [Woman \#27, 34 years old, partner HIV-status unknown]

\section{B. Deterrents to Having Children}

Men and women who did not want children cited financial reasons or already having enough children, often despite social and cultural pressures to have more children. Participants voiced concerns over orphaning a child, vertical transmission, or infecting a negative partner.

I want to be financially stable [before having a child], able to support myself and support the rest of the family. Another thing I am concerned about is that maybe she [partner] does not want to be HIV [infected]. I have never asked her if she is willing to take the risk of contracting HIV if we engage in sex. [Man \#13, 28 years old, partner HIV-negative]

In the community the issue of having children is important. If you have one, like I do, you find people saying that if this one dies then it is the end, so it's better if you have at least three.... I do things according to my plans and the way I think, I wouldn't 
want to have four children when I am unemployed just because I want to build a name for myself [Man \#12, 35 years old, partner HIV-status unknown]

As much as there are ARVs available and you know that you can still live, there is that element that you know that you are sick and there will come a time where you will leave your baby and you do not have relatives who will look after the child appropriately. [Woman \#26, 22 years old, partner HIV-status unknown]

Women expressed fears about the impact of pregnancy and childbirth on their health.

I am [HIV-] positive. If I keep on getting pregnant I might die myself. [Woman \#13, 31 years old, partner HIV-negative]

\section{Role of Men in Conception Decisions}

Women frequently reported that their partners desired the recent pregnancy, often despite the woman's preference not to become pregnant. This complicated negotiations regarding condom use, which most women relied on for contraception.

At times he would pretend he was using the condom when he was not. I told him that we should stop thinking about having a baby because I am sick, but he hoped for a child. [Woman, \#21, 33 years old, partner HIV-negative]

He asked me to have his baby because he doesn't have a child, but I told him that I'm not ready to have a baby yet ... we used to fight a lot about that. [Woman \#3, 25 years old, partner HIV-status unknown]

Male participants also described a desire to have children when their partner reportedly did not.

She said not now [to having children]. I wish to have more children because I feel that the two that I have are not enough. [Man \#19, 30 years old, partner HIVnegative]

\section{Pregnancy Planning}

We asked participants whether their recent pregnancy had been planned, whether it was desired by themselves and/or the partner, and how they and their partner felt about the referent pregnancy. Responses revealed that pregnancy intention occurs on a spectrum with a minority of pregnancies explicitly intended. The following quote is an example of a woman who explicitly planned and wanted her pregnancy:
I would tell him [husband] over the phone that I am waiting patiently for him to score. One day ... I bought a pregnancy test and I tested myself. God, two lines appeared... I went to the doctor who confirmed that I was pregnant. I kept the test I used. Even now it is still at home. [Woman \#15, 34 years old, partner HIVnegative]

Some women reported unplanned, but desired pregnancies. These women had hoped for pregnancy at some point in their future, did not use contraception, and engaged in unprotected sex.

I did want to have a child but I had not really planned which year it would be, but I wanted one... I was the one who wanted a child and I'm the only one who knew that. When I told him [partner] that I was pregnant, he did not have a problem with that. I have never used any [contraception.] [Woman \#18, 24 years old, partner HIV-negative]

Some attitudes around pregnancy were difficult to characterize, including women with unplanned pregnancy who reported happiness about their pregnancies. It was unclear if this reflected resigned acceptance or fertility desire.

'Did you plan this pregnancy?' No ... I am happy because even my ultrasound is good, yah, a baby is a baby. [Woman \#19, 33 years old, partner HIV-status unknown]

'Did you plan this pregnancy?' Not really. I kept asking myself where to from here, since I am going to be a mother, but now everything is just fine. I told myself that I'm pregnant and if the baby can come now, I will be fine. [Women \#14, 23 years old, partner HIV-status unknown]

Our sample also included women with unintended, unwanted pregnancies. For some with unplanned, unwanted pregnancies, partner response to the news of pregnancy influenced the woman's response.

That was my wish [not to have more children]. That is why I dated a married man, because I knew he would agree to use condoms. [Woman \#5, 28 years old, partner HIV-negative]

No, I was not happy at all [to be pregnant]. Maybe it would have made me happy if, when I told him about my pregnancy, he was happy. Instead, he said he didn't want a baby and told me that [my pregnancy] was my own problem. [Woman \#7, 31 years old, partner HIV-status unknown]

Use of contraception other than male condoms in this sample of pregnant or recently pregnant women was, 
unsurprisingly, low. Reasons for low use included fear of side effects, history of side effects, discontinuation of hormonal contraception for treatment of multi-drug-resistant tuberculosis, unplanned (including forced) sex, perceived personal, or partner infertility, or infrequent sexual intercourse.

\section{Horizontal Transmission Risk: Understandings and Behavior}

Mutual HIV testing, disclosure, and a basic understanding of horizontal HIV transmission risk are prerequisites for modifying periconception HIV-risk behavior. Most men and women in this sample reported HIV-status disclosure to their partner (Table 1). While many directly disclosed their HIV-status, several participants suggested their diagnosis through actions but without directly telling the partner the test results.

It was hard for me to tell him that I was positive. But I was not hiding my ARVs. He asked what medication I was taking. I said I am sick, I have a spine problem, and he understood. I then told him that we will have to use condoms when we have sex. [Woman \#6, 31 years old, partner status unknown]

When I found out I am HIV-positive, I was in a relationship with my current partner. Nothing changed because when I went for the test I told him and he said that when I come back with the results I should not tell him the outcome. I did not tell him, but I continued with him like before except we started using condoms consistently because I told him that the doctor said we should use condoms from that day onwards. [Woman \#20, 31 years old, partner status unknown]

Several participants did not disclose based on fear of partner response or beliefs about the partner's positive status.

I failed [to disclose my status] because I thought that he would say I am the one committing adultery. [Woman \#12, 29 years old, partner HIV-negative]

No, I have never [told my partner my status] because I can see that he knows that he is positive but he is just keeping it from me. He takes immune boosters and drinks mixtures that are made for HIV-positive people. [Woman \#30, 31 years old, partner status unknown]

Among women who planned pregnancies after knowing their HIV diagnosis, one did not disclose HIV-status to her partner. This woman believed that her partner was HIVpositive (Woman \#30, quoted above).
Many responses revealed that confusion about serodiscordance and fatalism about eventual seroconcordance (both partners becoming HIV-positive) led to riskier behavior. Hidden HIV, the window period (lag between HIV infection and development of detectable antibodies), divine intervention, and protected blood were offered as explanations for a sexual partner's discordant test results.

I think it's God's will that she did not get the virus from me. [Man \#14, 39 years old, partner HIVnegative]

He then asked me how it happens that he is negative and I am positive, and I told him about the window period. [Female \#11, 34 years old, partner HIVnegative]

He didn't have a problem [to use condoms] at the beginning, but as time went on he stopped using them saying if I am positive, he is also positive. He can't be negative while I am positive: maybe the virus is hidden but it is there. [Female \#13, 31 years old, partner HIV-negative]

Once a condom breaks, you ask yourself, 'What's the use? It has already broken and now she's got it [HIV] ... So, let's continue without a condom.' [Man \#6, 31 years old, partner HIV-negative]

Some women who planned pregnancy described risking horizontal transmission with her partner in order to conceive; in some cases, the decision to take the risk was made by the negative partner. None of the male participants reported planning a pregnancy with a partner after HIV diagnosis, thus we only report women's perspectives on this issue. 1

... he was the one who decided he wanted another child... I was afraid. I told him that what we are doing [unprotected sex] is not right because he might get infected. And if he goes back to test and is positive, he will blame me. He said if that is supposed to happen, then it will happen. [Woman \#11, 34 years old, HIV-negative partner]

I do not want him to contract it [HIV] but he is a man and they can be very stubborn. He says what's wrong if he dies because of this virus? All he wants is a child and it does not matter if he gets HIV. [Woman \#21, 33 years old, HIV-negative partner]

\footnotetext{
${ }_{1}^{1}$ Recent partner pregnancy was not an inclusion criteria for male participants, which may explain the discrepancy between planned pregnancies since diagnosis for men and women.
} 
III. Knowledge of Periconception Strategies to Reduce the Risk of Horizontal HIV Transmission

Most couples were not aware of non-condom-based strategies to reduce the risk of horizontal HIV transmission. Responses suggested openness to advice for minimizing periconception transmission. Participants often assumed that healthcare workers had advice to offer, but few had sought it.

What we usually talk about is that her heart is broken because she still wants to have a child. But the question is how, since she does not have a child with me. Unfortunately, I do not have answers to her question. I know that it is difficult to have a child in our situation. I think it would be my responsibility to consult doctors who can to tell us what we should do. [Man \#7, 40 years old, partner HIV-negative]

If we had enough information about how we can have a child safely, we would have one by now. I hear people talk about it but it is better to hear from somebody who is knowledgeable. [Man \#11, 33 years old, partner negative]

Two participants had heard of traditional healers offering safer conception strategies but neither participant had firsthand knowledge. A number of participants sought information from healthcare providers and the internet in order to learn about and, in some cases, carry-out safer conception strategies. This included delaying conception until the positive partner's viral load was suppressed and home manual insemination (for male-uninfected couples: the man ejaculates into a condom or other receptacle, then semen is inserted into the vaginal canal via a syringe or reversed condom). Some participants mentioned microbicides and oral prophylaxis as potential strategies.

After finding out that my viral load was very low, even undetectable, he [husband] decided we should take a chance and see what is going to happen. He said that he has taken that decision, I am not forcing him to take it. Then we just took a chance. [Woman \#4, 28 years old, partner HIV-negative]

A doctor gave us a [syringe] which we had to use after sex to withdraw sperm [from the condom to insert into the woman]. ... We are both aware that I am positive and so we would use a condom all the time... and we received advice from the doctor on how to use the syringe so that he [partner] does not get infected. [Woman \#25, 32 years old, partner HIVnegative]

When we discuss the topic of children, we question how we are going to have a child. I'm positive and she is negative, it impossible. But she went as far as the internet to check. She saw something about sperm washing on the internet. [Man \#5, 30 years old, partner negative]

I heard about this thing... on the news. I do not know its name but it's a gel substance. I don't know whether it's the negative or positive that takes this substance. [Male \#6, 31 years old, partner HIV-negative]

\section{Motivation to Protect the Baby Results in Reduction in Risk Behavior}

Female participants reported that, upon pregnancy diagnosis, she and her partner modified behavior to protect the baby, including improved ARV adherence, abstinence, condom use, and avoiding concurrent partners. Some modified behavior in order to avoid sexually transmitted infections and transmitted HIV drug resistance (in case her partner became positive). In other cases, the motives for protection were not scientifically informed (e.g., avoiding damage from seminal fluid).

Since I got pregnant, we no longer have sex...He is trying to make sure my CD4 count goes up and the baby doesn't get infected. [Woman \#5, 31 years old, partner HIV-negative]

Yes, [he agreed to use a condom] for the sake of the baby. [Woman \#7, 28 years old, partner HIV-status unknown]

\section{Discussion}

Our findings expand on prior work demonstrating that people living with HIV in sub-Saharan Africa have deeplyingrained personal and culturally-embedded reasons for having children [16, 27, 29, 54, 55]. These beliefs remain intact when HIV-positive individuals have partners of negative or unknown HIV-status [12]. Practical deterrents to having children include financial constraints and having met procreation goals. HIV-specific fears of vertical transmission, orphaning a child, horizontal transmission, and peripartum health are also factors; each of these may be mitigated with improved access to ART and PMTCT programs [34, 56]. These findings add to a robust global literature arguing for improved counseling and care services for HIV-positive individuals who choose to have children [17, 21, 34, 57-60].

Independent of fertility goals, many study participants were confused by the nature of serodiscordance, leading to riskier behavior, as described by Bunnell and colleagues in Uganda [61]. These findings suggest that routine 
couples-based counseling about serodiscordance may be a critical first-step to safer sex and/or safer periconception behavior [62]. In addition, while the majority of participants had disclosed their HIV-status to the primary partner, many had not. Strategies for navigating the complexities of disclosure will be a necessary component of any safer conception intervention [62-64].

Among participants who planned pregnancies with a serodiscordant partner, some individuals or partners had sought advice from healthcare providers or the internet, but the majority of participants did not know how to minimize sexual transmission risk while allowing for conception. Some described knowingly risking horizontal HIV transmission in order to conceive. These data support a harmreduction approach to reproductive counseling: in the absence of counseling that acknowledges reproductive goals, HIV-discordant couples who choose to have children take unnecessary risks to conceive [45].

While prior work has suggested patient reluctance to engage with healthcare workers in reproductive counseling [15, 16, 60, 65-68], many study participants had received advice about childbearing from healthcare workers or suggested that clinicians might serve as helpful resources. This may have been specific to our study site, or may indicate evolving attitudes among healthcare workers towards the reproductive goals of people living with HIV. If these findings are replicated on a larger scale, a periconception counseling intervention may be successfully delivered in healthcare settings. Because a combined prevention program will likely include suppressive ART for the positive partner [48] or periconception oral or topical PrEP [46, 47, 49, 50, 69], it may be important to base such interventions in a healthcare setting. In addition, because HIV-positive men and women may suffer from infertility [70-74], clinical consultation to assess fertility prior to recommending conception strategies will be necessary.

The finding that couples modify behavior to protect the baby after conception may reflect PMTCT counseling messages at this study site. Regardless, uptake of behavioral change was high, suggesting that promoting safer conception interventions as a strategy to protect the child may be successful.

Viral load suppression with ART is an important strategy to reduce sexual transmission for serodiscordant couples [48, $75,76]$. A minority $(9 / 22$ or $40 \%)$ of women who became pregnant after HIV diagnosis were on ART at the time of conception and only one participant mentioned ART as a strategy to minimize periconception transmission. Encouraging couples to delay conception until the positive partner meets criteria for ART and achieves a suppressed viral load could reduce transmission by $96 \%$ [48].

The data support a broad approach to family planning messages. A minority of pregnancies were explicitly planned, some were explicitly unintended and unwanted, and the remainder occurred on a spectrum between these two extremes. Women who do not plan pregnancy but want to become pregnant may be difficult to identify with standard questions that ask if they plan to become pregnant. More nuanced questions that address fertility desire should be incorporated [77]. Men play a dominant role in pregnancy decisions, as supported by prior work in South Africa, Kenya, Malawi, Uganda, and Nigeria [12, 14-16, 27, 54, 78]. These data suggest that a reproductive counseling intervention must target men as well as women, and must include promotion of contraception other than male condoms (e.g., IUD, hormonal contraception) to avoid unwanted pregnancy. Interventions to engage men in contraception and family planning have been effective in several sub-Saharan African settings [78-80].

\section{Limitations}

These qualitative data from a small, purposive sample are not generalizable. In addition, many participants had relatively high education and were employed and may not be representative of patients who attend free government clinics. By design, we interviewed the HIV-positive member of serodiscordant couples, yet uninfected partners would be the target population for a prevention intervention and should be the focus of future research. Socially desirable responses may have affected some of the findings (e.g., reporting of safer sex practices by women enrolled in a PMTCT program).

\section{Conclusions}

These data emphasize the importance of childbearing to HIV-discordant couples and describe a paucity of known strategies for reducing periconception transmission, but reveal openness to safer conception advice and uptake of behavior change to protect the unborn child. The findings support expanding existing interventions to promote safer sex and to prevent unwanted or unintended pregnancy, including couples-based counseling about serodiscordance and promotion of contraception other than male condoms. The crucial male role in pregnancy decisions suggests the importance of targeting men in safer conception interventions. Individuals in our sample were amenable to healthcare worker advice, suggesting that future combination prevention strategies could be successfully implemented in a healthcare setting.

Acknowledgments We would like to thank study participants for their participation and our research assistants for their work on this project. Dr. Matthews received funding support from the American Society of Tropical Medicine and Hygiene/Burroughs Wellcome Fund Postdoctoral Fellowship in Tropical Infectious Diseases and 
from the Mark and Lisa Schwartz Family Foundation. Dr. Bangsberg was supported by the Mark and Lisa Schwartz Family Foundation and by a K24 award (NIMH MH087227).

Open Access This article is distributed under the terms of the Creative Commons Attribution Noncommercial License which permits any noncommercial use, distribution, and reproduction in any medium, provided the original author(s) and source are credited.

\section{References}

1. UNAIDS. Global report: UNAIDS report on the global AIDS epidemic 2010. Geneva: WHO.

2. Guthrie BL, de Bruyn G, Farquhar C. HIV-1-discordant couples in sub-Saharan Africa: explanations and implications for high rates of discordancy. Curr HIV Res. 2007;5(4):416-29.

3. Dunkle KL, Stephenson R, Karita E, Chomba E, Kayitenkore K, Vwalika C, et al. New heterosexually transmitted HIV infections in married or cohabiting couples in urban Zambia and Rwanda: an analysis of survey and clinical data. Lancet. 2008;371(9631): 2183-91.

4. Chen JL, Philips KA, Kanouse DE, Collins RL, Miu A. Fertility desires and intentions of HIV-positive men and women. Fam Plann Perspect. 2001;33(suppl 4):144-52.

5. Frodsham LC, Boag F, Barton S, Gilling-Smith C. Human immunodeficiency virus infection and fertility care in the United Kingdom: demand and supply. Fertil Steril. 2006;85(2):285-9.

6. Panozzo L, Battegay M, Friedl A, Vernazza PL. High risk behaviour and fertility desires among heterosexual HIV-positive patients with a serodiscordant partner-two challenging issues. Swiss Med Wkly. 2003;133(7-8):124-7.

7. Heard I, Sitta R, Lert F. Reproductive choice in men and women living with HIV: evidence from a large representative sample of outpatients attending French hospitals (ANRS-EN12-VESPA Study). AIDS. 2007;21(1):S77-82.

8. Myer L, Morroni C, Rebe K. Prevalence and determinants of fertility intentions of HIV-infected women and men receiving antiretroviral therapy in South Africa. AIDS Patient Care STDS. 2007;21(4):278-85.

9. Brubaker SG, Bukusi EA, Odoyo J, Achando J, Okumu A, Cohen CR. Pregnancy and HIV transmission among HIV-discordant couples in a clinical trial in Kisumu, Kenya. HIV Med. 2011; 12(5):316-21.

10. Kaida A, Andia I, Maier M, Strathdee SA, Bangsberg DR, Spiegel J, et al. The potential impact of antiretroviral therapy on fertility in sub-Saharan Africa. Curr HIV/AIDS Rep. 2006;3(4): 187-94.

11. Maier M, Andia I, Emenyonu N, Guzman D, Kaida A, Pepper L, Hogg R, Bangsberg DR. Antiretroviral therapy is associated with increased fertility desire, but not pregnancy or live birth, among $\mathrm{HIV}+$ women in an early HIV treatment program in rural Uganda. AIDS Behav. 2009;13(1):28-37.

12. Beyeza-Kashesya J, Ekstrom AM, Kaharuza F, Mirembe F, Neema S, Kulane A. My partner wants a child: a cross-sectional study of the determinants of the desire for children among mutually disclosed sero-discordant couples receiving care in Uganda. BMC Public Health. 2010;10:247.

13. Homsy J, Bunnell R, Moore D, King R, Malamba S, Nakityo R, et al. Reproductive intentions and outcomes among women on antiretroviral therapy in rural Uganda: a prospective cohort study. PLoS ONE. 2009;4(1):e4149.

14. Nakayiwa S, Abang B, Packel L, Lifshay J, Purcell DW, King R, et al. Desire for children and pregnancy risk behavior among
HIV-infected men and women in Uganda. AIDS Behav. 2006; 10(4):S95-104.

15. Awiti Ujiji O, Ekstrom AM, Ilako F, Indalo D, Rubenson B. "I will not let my HIV-status stand in the way." Decisions on motherhood among women on ART in a slum in Kenya-a qualitative study. BMC Womens Health. 2010;10:13.

16. Cooper D, Harries J, Myer L, Orner P, Bracken H, Zweigenthal V. "Life is still going on": reproductive intentions among HIVpositive women and men in South Africa. Soc Sci Med. 2007; 65(2):274-83.

17. Cooper D, Moodley J, Zweigenthal V, Bekker LG, Shah I, Myer L. Fertility intentions and reproductive health care needs of people living with HIV in Cape Town, South Africa: implications for integrating reproductive health and HIV care services. AIDS Behav. 2009;13(1):38-46.

18. Moodley D, Esterhuizen TM, Pather T, Chetty V, Ngaleka L. High HIV incidence during pregnancy: compelling reason for repeat HIV testing. AIDS. 2009;23(10):1255-9.

19. Kharsany AB, Hancock H, Frohlich JA, Humphries HR, Abdool Karim SS, Abdool Karim Q. Screening for 'window-period' acute HIV infection among pregnant women in rural South Africa. HIV Med. 2010;11(10):661-5.

20. Mugo NR, Heffron R, Donnell D, Wald A, Were EO, Rees H, et al. Increased risk of HIV-1 transmission in pregnancy: a prospective study among African HIV-1-serodiscordant couples. AIDS. 2011;25(15):1887-95.

21. Guthrie BL, Choi RY, Bosire R, Kiarie JN, Mackelprang RD, Gatuguta A, et al. Predicting pregnancy in HIV-1-discordant couples. AIDS Behav. 2010;14(5):1066-71.

22. Van Balen F. Involuntary childlessness: a neglected problem in poor-resource areas. Hum Reprod. 2008;2008:25-8.

23. Dyer SJ, Abrahams N, Mokoena NE, Lombard CJ, van der Spuy ZM. Psychological distress among women suffering from infertility in South Africa: a quantitative assessment. Hum Reprod. 2005;20(7):1938-43.

24. Sonko S. Fertility and culture in Sub-Saharan Africa: a review. Inter Soc Sci J. 1994;46(3):397-411.

25. Rutstein SO, Shah IH. Infecundity, infertility and childlessness in developing countries. Calverton: ORC Macro; 2004.

26. Wood K, Jewkes R. Violence, rape, and sexual coercion: everyday love in a South African township. Gend Dev. 1997;5(Suppl 2):41-6.

27. Smith DJ, Mbakwem BC. Life projects and therapeutic itineraries: marriage, fertility, and antiretroviral therapy in Nigeria. AIDS. 2007;21(Suppl 5):S37-41.

28. Preston-Whyte E. Culture, context and behaviour: anthropological perspectives on fertility in Southern Africa. South Afr J Demogr. 1988;2(1):13-23.

29. Nduna M, Farlane L. Women living with HIV in South Africa and their concerns about fertility. AIDS Behav. 2009;13(1):62-5.

30. Harrison A, O'Sullivan LF. In the absence of marriage: long-term concurrent partnerships, pregnancy and HIV risk dynamics among South African young adults. AIDS Behav. 2010;14: 991-1000.

31. Dyer SJ, Abrahams N, Hoffman M, van der Spuy ZM. "Men leave me as I cannot have children": women's experiences with involuntary childlessness. Hum Reprod. 2002;17(Suppl 6): 1663-8.

32. Richter L. A survey of reproductive health issues among urban black youth in South Africa: final grant report. Pretoria, South Africa: Center for Epidemiological Research in South Africa: Medical Research Council;1996.

33. Varga CA, Makubalo LE. Sexual non-negotiation. Agenda. 1996;28:31-8.

34. Myer L, Carter RJ, Katyal M, Toro P, El-Sadr WM, Abrams EJ. Impact of antiretroviral therapy on incidence of pregnancy among 
HIV-infected women in sub-Saharan Africa: a cohort study. PLoS Med. 2010;7(2):e1000229.

35. Makumbi FE, Nakigozi G, Reynolds SJ, Ndyanabo A, Lutalo T, Serwada D, et al. Associations between HIV antiretroviral therapy and the prevalence and incidence of pregnancy in Rakai, Uganda. AIDS Res Treat. 2011;2011:519492.

36. Bujan L, Hollander L, Coudert M, Gilling-Smith C, Vucetich A, Guibert J, et al. Safety and efficacy of sperm washing in HIV-1serodiscordant couples where the male is infected: results from the European CREAThE network. AIDS. 2007;21(14):1909-14.

37. Nicopoullos JD, Almeida P, Vourliotis M, Gilling-Smith C. A decade of the United Kingdom sperm-washing program: untangling the transatlantic divide. Fertil Steril. 2010;94(6):2458-61.

38. Barreiro P, del Romero J, Leal M, Hernando V, Asencio R, de Mendoza $\mathrm{C}$, et al. Natural pregnancies in HIV-serodiscordant couples receiving successful antiretroviral therapy. J Acquir Immune Defic Syndr. 2006;43(3):324-6.

39. Mandelbrot L, Heard I, Henrion-Geant E, Henrion R. Natural conception in HIV-negative women with HIV-infected partners. Lancet. 1997;349(9055):850-1.

40. Auvert B, Taljaard D, Lagarde E, Sobngwi-Tambekou J, Sitta R, Puren A. Randomized, controlled intervention trial of male circumcision for reduction of HIV infection risk: the ANRS 1265 Trial. PLoS Med. 2005;2(11):e298.

41. Bailey RC, Moses S, Parker CB, Agot K, Maclean I, Krieger JN, et al. Male circumcision for HIV prevention in young men in Kisumu, Kenya: a randomised controlled trial. Lancet. 2007; 369(9562):643-56.

42. Gray RH, Kigozi G, Serwadda D, Makumbi F, Watya S, Nalugoda F, et al. Male circumcision for HIV prevention in men in Rakai, Uganda: a randomised trial. Lancet. 2007;369(9562): 657-66.

43. Grosskurth H, Mosha F, Todd J, Senkoro K, Newell J, Klokke A, et al. A community trial of the impact of improved sexually transmitted disease treatment on the HIV epidemic in rural Tanzania: 2. Baseline survey results. AIDS. 1995;9(8):927-34.

44. Wawer MJ, Gray RH, Sewankambo NK, Serwadda D, Paxton L, Berkley S, et al. A randomized, community trial of intensive sexually transmitted disease control for AIDS prevention, Rakai, Uganda. AIDS. 1998;12(10):1211-25.

45. Matthews L, Mukherjee J. Strategies for harm reduction among HIV-affected couples who want to conceive. AIDS Behav. 2009;13(1):S5-11.

46. Grant RM, Lama JR, Anderson PL, McMahan V, Liu AY, Vargas $\mathrm{L}$, et al. Preexposure chemoprophylaxis for HIV prevention in men who have sex with men. N Engl J Med. 2010;363(27): 2587-99.

47. Karim QA, Karim SS, Frohlich JA, Grobler AC, Baxter C, Mansoor LE, et al. Effectiveness and safety of tenofovir gel, an antiretroviral microbicide, for the prevention of HIV infection in women. Science. 2010;329(5996):1168-74.

48. Cohen MS, Chen YQ, McCauley M, Gamble T, Hosseinipour MC, Kumarasamy N, et al. Prevention of HIV-1 infection with early antiretroviral therapy. N Engl J Med. 2011;365(6):493-505.

49. University of Washington International Clinical Research Center. Pivotal study finds that HIV medications are highly effective as prophylaxis against HIV infection in men and women in Africa. 13 July 2011.

50. CDC. CDC Trial and Another Major Study Find PrEP Can Reduce Risk of HIV Infection among Heterosexuals. 13 July 2011.

51. National Department of Health South Africa. National Antenatal Sentinel HIV and Syphilis Prevalence Survey in South Africa, 2009. Pretoria: National Department of Health. 2010.
52. Strauss A, Corbin J. Basics of qualitative research: Techniques and procedures for developing grounded theory. Thousand Oaks, CA: Sage Publications; 1998.

53. Ulin PR, Robinson ET, Tolley EE. Qualitative methods in public health: a field guide for applied research. San Francisco: JolleyBass; 2005.

54. Yeatman S. HIV infection and fertility preferences in rural malawi. Stud Fam Plann. 2009;40(4):261-76.

55. Beyeza-Kashesya J, Kaharuza F, Mirembe F, Neema S, Ekstrom AM, Kulane A. The dilemma of safe sex and having children: challenges facing HIV sero-discordant couples in Uganda. Afr Health Sci. 2009;9(1):2-12.

56. Kaida A, Lima VD, Andia I, Kabakyenga J, Mbabazi P, Emenyonu N, et al. The WHOMEN's scale and the association with fertility intentions and sexual behaviours among HIV-positive women in Uganda. AIDS Behav. 2009;13(1):72-81.

57. Kaida A, Bangsberg DR, Gray G, Hogg RS, King R, Miller CL. Editorial: introduction to the supplement on HIV, HAART, and fertility in sub-Saharan Africa. AIDS Behav. 2009;13(1):1-4.

58. Mantell JE, Smit JA, Stein ZA. The right to choose parenthood among HIV-infected men and women. J Public Health Policy. 2009;30(4):367-78.

59. Segurado AC, Paiva V. Rights of HIV positive people to sexual and reproductive health: parenthood. Reprod Health Matters. 2007;15(29 Suppl):27-45.

60. Paiva V, Filipe EV, Santos N, Lima TN, Segurado A. The right to love: the desire for parenthood among men living with HIV. Reprod Health Matters. 2003;11(22):91-100.

61. Bunnell RE, Nassozi J, Marum E, Mubangizi J, Malamba S, Dillon B, et al. Living with discordance: knowledge, challenges, and prevention strategies of HIV-discordant couples in Uganda. AIDS Care. 2005;17(8):999-1012.

62. Kairania R, Gray RH, Kiwanuka N, Makumbi F, Sewankambo NK, Serwadda D, et al. Disclosure of HIV results among discordant couples in Rakai, Uganda: a facilitated couple counselling approach. AIDS Care. 2010;22(9):1041-51.

63. Matovu JK. Preventing HIV transmission in married and cohabiting HIV-discordant couples in sub-Saharan Africa through combination prevention. Curr HIV Res. 2010;8(6):430-40.

64. King R, Katuntu D, Lifshay J, Packel L, Batamwita R, Nakayiwa $\mathrm{S}$, et al. Processes and outcomes of HIV serostatus disclosure to sexual partners among people living with HIV in Uganda. AIDS Behav. 2008;12(2):232-43.

65. Kaida A, Laher F, Strathdee SA, Janssen PA, Money D, Hogg $\mathrm{RS}$, et al. Childbearing intentions of HIV-positive women of reproductive age in Soweto, South Africa: the influence of expanding access to HAART in an HIV hyperendemic setting. Am J Public Health. 2011;101(2):350-8.

66. Finocchario-Kessler S, Dariotis JK, Sweat MD, Trent ME, Keller JM, Hafeez Q, et al. Do HIV-infected women want to discuss reproductive plans with providers, and are those conversations occurring? AIDS Patient Care STDS. 2010;24(5):317-23.

67. Orner P, Cooper D, Myer L, Zweigenthal V, Bekker LG, Moodley J. Clients' perspectives on HIV/AIDS care and treatment and reproductive health services in South Africa. AIDS Care. 2008;20(10):1217-23.

68. McCarraher D, Cuthbertson C, Kung'u D, Otterness C, Johnson L, Magiri G. Sexual behavior, fertility desires and unmet need for family planning among home-based care clients and caregivers in Kenya. AIDS Care. 2008;20(9):1057-65.

69. Matthews LT, Baeten JM, Celum C, Bangsberg DR. Periconception pre-exposure prophylaxis to prevent HIV transmission: benefits, risks, and challenges to implementation. AIDS. 2010; 24(13):1975-82. 
70. Coll O, Lopez M, Vidal R, Figueras F, Suy A, Hernandez S, et al. Fertility assessment in non-infertile HIV-infected women and their partners. Reprod Biomed Online. 2007;14(4):488-94.

71. Gingelmaier A, Wiedenmann K, Sovric M, Mueller M, Kupka MS, Sonnenberg-Schwan U, et al. Consultations of HIV-infected women who wish to become pregnant. Arch Gynecol Obstet. 2011;283(4):893-8.

72. Kehl S, Weigel M, Muller D, Gentili M, Hornemann A, Sutterlin M. HIV-infection and modern antiretroviral therapy impair sperm quality. Arch Gynecol Obstet. 2011;284:229-33.

73. Kongnyuy EJ, Wiysonge CS. Association between fertility and HIV-status: what implications for HIV estimates? BMC Public Health. 2008;8:309.

74. Dhont N, van de Wijgert J, Vyankandondera J, Busasa R, Gasarabwe A, Temmerman M. Results of infertility investigations and follow-up among 312 infertile women and their partners in Kigali, Rwanda. Trop Doct. 2011;41(2):96-101.

75. Reynolds SJ, Makumbi F, Nakigozi G, Kagaayi J, Gray RH, Wawer M, et al. HIV-1 transmission among HIV-1 discordant couples before and after the introduction of antiretroviral therapy. AIDS. 2011;25:473-7.
76. Donnell D, Baeten JM, Kiarie J, Thomas KK, Stevens W, Cohen $\mathrm{CR}$, et al. Heterosexual HIV-1 transmission after initiation of antiretroviral therapy: a prospective cohort analysis. Lancet. 2010;375(9731):2092-8.

77. Klerman LV. The intendedness of pregnancy: a concept in transition. Matern Child Health J. 2000;4(3):155-62.

78. UNDP/UNFPA/WHO/World Bank Special Programme of Research Development and Research Training in Human Reproduction. Programming for male involvement in reproductive health. Report of the meeting of WHO Regional advisors in reproductive health WHO/PAHO; Washington DC. Sept 2001. Geneva: WHO; 2002.

79. Shattuck D, Kerner B, Gilles K, Hartmann M, Ng'ombe T, Guest G. Encouraging contraceptive uptake by motivating men to communicate about family planning: the Malawi male motivator project. Am J Public Health. 2011;101:1089-95.

80. Terefe A, Larson CP. Modern contraception use in Ethiopia: does involving husbands make a difference? Am J Public Health. 1993;83(11):1567-71. 